\title{
Pulmonary arterial hypertension: diagnosis and treatment
}

\author{
Marcin Sadowski, Agnieszka Janion-Sadowska, Agnieszka Łętek, Grzegorz Raczyński, Łukasz Zandecki \\ Świętokrzyskie Cardiology Center, Regional District Hospital, Kielce, Poland \\ Head of Department: Prof. Marianna Janion
}

Studia Medyczne 2013; 29 (3): 273-279

Key words: pulmonary hypertension, pulmonary arterial hypertension, diagnosis, treatment.

\begin{abstract}
Pulmonary arterial hypertension is one of the clinical groups of arterial hypertension. It is a rare, chronic disease with a very poor prognosis. Diagnostic procedures ruling out different causes of present symptoms and other forms of pulmonary hypertension are difficult and specific. Current European guidelines recommend combined treatment with endothelin receptor antagonist, prostanoids, and phosphodiesterase type 5 inhibitors.
\end{abstract}

\section{Introduction}

Pulmonary hypertension (PH) is not a homogeneous clinical entity. It often occurs in heart and lung diseases. The first description of "pulmonary arteriosclerosis" comes from the nineteenth century and it was created by the German physician and pathologist Ernst von Romberg [1]. Until 1998 there was the traditional division of $\mathrm{PH}$ into primary, when it is impossible to establish the etiological agent, and secondary, which occurs in the course of left heart disease, lung and bronchitis diseases as well as pulmonary embolism. Currently $\mathrm{PH}$ is defined as a clinical, hemodynamic and pathophysiologic condition in which the value of the average arterial pressure in the pulmonary artery (mean pulmonary artery pressure - mPAP) in the direct measurement taken at rest during right heart catheterization is greater than or equal to $25 \mathrm{~mm} \mathrm{Hg}$ [2-4].

The purpose of this paper is to summarize current knowledge about pulmonary arterial hypertension. The current classification of $\mathrm{PH}$, published in 2008 in Dana Point, California, includes separations which occur in the range of - takes into account differences in the mechanism, pathology, pathophysiology and clinical diagnosis, as well as prognosis and responses to the therapy $[2,3]$. Based on them there have been isolated 5 groups containing numerous clinical categories of pulmonary hypertension (Table 1). The common feature of all five clinical groups are increased hemodynamic parameters which are the value of mPAP and pulmonary vascular resistance (PVR).

The frequency of different clinical categories is difficult to establish. In a study of 4579 people with systolic blood pressure greater than $40 \mathrm{~mm} \mathrm{Hg}$ which was echocardiographically confirmed, pulmonary hypertension was present in $10.5 \%$ of patients [3]. The most common causes of $\mathrm{PH}$ were: left heart disease $(78.7 \%$ - group 2), lung diseases and hypoxia (9.7\% - group 3), pulmonary arterial hypertension (4.2\% - group 1$)$ and pulmonary hypertension which occurs in patients with chronic thromboembolism $(0.6 \%$ - group 4$)$. The cause of pulmonary hypertension in $6.8 \%$ of patients was not established [2]. The classification from 2008 identified two main hemodynamic profiles of $\mathrm{PH}$ : precapillary and postcapillary. Precapillary profile is characterized by increased $\mathrm{mPAP} \geq 25 \mathrm{~mm} \mathrm{Hg}$ and the normal pulmonary capillary wedge pressure (PCWP) $\leq 15 \mathrm{~mm} \mathrm{Hg}$, which is present in clinical group 1 (PAH) and in clinical groups 3,4 and 5. Postcapillary $\mathrm{PH}$ profile is characterized by increased mPAP $\geq 25 \mathrm{~mm} \mathrm{Hg}$ and increased PCWP $>15 \mathrm{~mm} \mathrm{Hg}$. It can be found in clinical group 2 (PH in the process of left heart disease) $[1,5]$.

\section{Definition, forms and epidemiology of pulmonary arterial hypertension}

Pulmonary arterial hypertension (PAH) is one of the clinical categories of PH. It is defined as a clinical and hemodynamic condition characterized by the presence of precapillary pulmonary hypertension in the absence of other causes of such pressure, that is after exclusion of lung diseases, chronic thromboembolic disease and pulmonary hypertension caused by unknown, multi-factor mechanisms. It is a disease with poor prognosis, so far rarely recognized because of diagnostic difficulties. The progress of diagnostic methods in recent years and better understanding of the nature of $\mathrm{PAH}$ resulted in greater interest in this disease unit. Idiopathic PAH, heritable $\mathrm{PAH}$, high blood pressure resulting from the use of drugs or toxins associated with connective tissue disease, HIV infection, portal hypertension, congenital heart diseases, schistosomiasis, chronic hemolytic anemia, and persistent pulmonary hypertension of the newborn exhibit a comparable clinical picture and hemo- 
Table 1. Clinical classification of pulmonary hypertension. Based on ref. [2, 3]

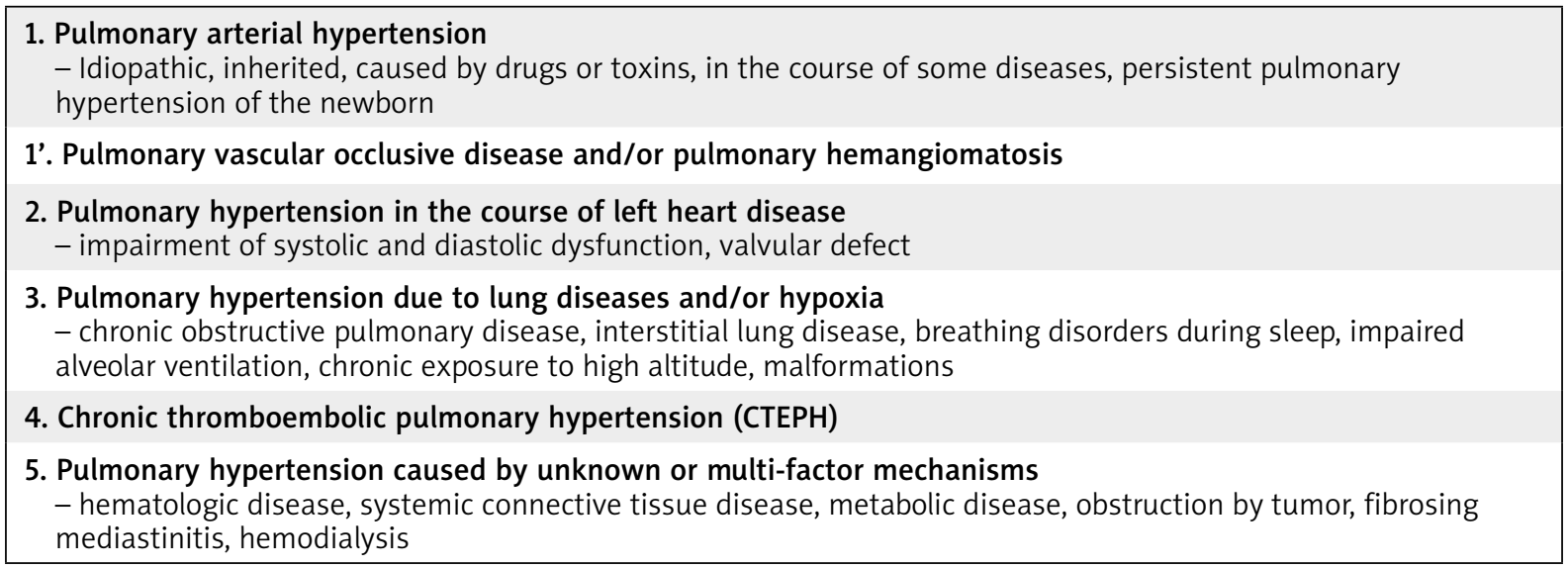

dynamic changes, as well as the same pathologic pulmonary microcirculation changes [2].

Based on European registers it is estimated that the morbidity in the population is $15-50 / 1 \mathrm{~m}$ inhabitants and incidence proportion is $2.4 / 1 \mathrm{~m} / 1$ year. Due to the current difficulty in identification, it appears that the actual incidence of PAH may be larger, e.g. in the 1960s and 1990s as well as now we can observe a significant increase in the incidence of PAH associated with taking medication to reduce appetite. Women suffer 1.7 times more often than men. The average age at diagnosis is 36 years [6].

The frequency of individual forms and diseases leading to PAH is difficult to determine. In the register of 17 university centers in France, which include 647 patients, idiopathic PAH was found in $39.2 \%$, connective tissue disease in $15.3 \%$, congenital heart disease in $11.3 \%$, portal hypertension in $10.4 \%$, the use of anorectic drugs in 9.5\%, HIV infection in $6.2 \%$, heritable PAH in $3.9 \%$ and other forms in $14.2 \%$ of patients [7]. Systemic diseases of the connective tissue of PAH occur most frequently in patients with scleroderma (6-60\%), especially in its limited form, in $4-14 \%$ of patients with systemic lupus erythematosus, in half of the patients with mixed connective tissue disease and in every fifth patient with rheumatoid arthritis. In congenital heart diseases it occurs in $30 \%$ of patients with systemic-pulmonary, practically in all patients with patent ductus arteriosus, in half of patient with ventricular septal defect, and rarely (10\%) in those with atrial septal defect [2].

\section{Pulmonary arterial hypertension - pathogenesis}

The exact cause defined as the initiating factor in the occurrence of PAH is unknown. Already in the early stages of the disease as a result of genetic predisposition and risk factors (connective tissue disease, congenital, septal heart defects, drugs that reduce appetite, HIV infection, liver disease, etc.) there occur endothelial dysfunction and balance disturbances between vasoconstrictive, promitogenic, vasodilating and antimitogenic factors. This leads to the reduced production of vasodilators (nitric oxide, prostacyclin, vasoactive intestinal peptide (VIP)) and excessive production of vasoconstrictor substances (endothelin, thromboxane $A_{2}$, angiopoietin). The spasm of small pulmonary arteries with a diameter below 500 microns is considered as an early component in the development of PAH. In the further process there is proliferation of endothelial cells and smooth muscle cells. Consequently it leads to rebuilding the walls of the blood vessels and increased vascular resistance within the pulmonary circulation. It should be noted that proliferation and associated occlusive pulmonary changes apply to all layers on walls of small pulmonary arteries - endothelium, tunica intima, media and tunica externa. In addition a very characteristic symptom is the presence of plexiform lesions which are focal proliferation of vascular channels surrounded by myofibroblasts and smooth muscle cells. In the pathophysiological chain the role of excessive activation of proinflammatory and prothrombotic factors is also important. In summary, these changes involve dysfunction of endothelial secretion and proliferation which limits the vascular bed [2-4].

The described changes go on regardless of the etiology of PAH and are identical in all clinical disorders in group 1. These changes inevitably lead to an increased pulmonary vascular resistance. This is followed by an increase in MPAP as a compensatory mechanism that maintains pulmonary blood flow, which increases afterload of the right ventricle (RV) and over some time leads to hypertrophy, dilatation and tricuspid insufficiency. Another response of RV to afterload is an increase of central venous pressure, enlargement of the liver, lower extremities edema and transudation into body cavities. It gradually develops into a complete picture of RV failure, with an increase in troponins as an expression of cardiomyocyte dam- 
age. In the final period it leads to low cardiac output and death.

\section{Diagnosis of pulmonary hypertension and pulmonary arterial hypertension}

The diagnosis of PAH is based on the recognition of typical symptoms of $\mathrm{PH}$ and differentiation of its characteristic categories and clinical groups.

\section{Clinical picture}

The $\mathrm{PH}$ clinical picture is non-specific. The earliest symptom is progressive exertional dyspnea and reduction in exercise tolerance. These symptoms may suggest disease of the heart, lungs, anemia, neurovegetative dystonia, etc. The common symptoms but non-specific and not very severe, especially in the early stages of the disease, include syncope and presyncope, occurring during exercises, and chest pain. On a physical examination there are no pathognomonic symptoms. Advanced stages of RV failure exhibit RV lift, strengthening of the second heart sound, holosystolic murmur of tricuspid insufficiency, diastolic murmur of pulmonary regurgitation, a third tone, extension of jugular veins, hepatomegaly, peripheral edema and transudation into body cavities [8].

\section{Electrocardiography examination}

The electrocardiography examination has low sensitivity (55\%) and specificity (70\%). In advanced stages there are overload and overgrowth of RV which include: right axis deviation $>90^{\circ}$, approximately $80 \%$ of the $\mathrm{S}$ wave in I, aVL $>1.5 \mathrm{~mm}$, transition zone V5-V6,
QS in III, aVF, inversion T wave in III, aVF, V1-V4, and low voltage in the limb leads [9] (Figure 1).

\section{Radiological chest examination}

In the initial stage of the disease chest X-ray shows no significant abnormalities. In the advanced period, especially in idiopathic PAH, the test is abnormal in $90 \%$ of patients. Pulmonary artery enlargement, straightening of the cardiac waistline, peripheral hypovascularity, and extension of the right atrium and the right ventricle are typical findings (Figure 2). X-ray changes do not correlate with the severity of the disease [10].

\section{Echocardiography examination}

The echocardiography examination in the diagnosis of $\mathrm{PH}$ is the most useful of the other non-invasive additional investigations. Based on the assessment of the maximum regurgitant velocity through the tricuspid valve (TVIvel), the magnitude of systolic pulmonary artery pressure (sPAP) and RV dilatation, extension of the pulmonary artery, reducing acceleration time of blood ejection from the right ventricle (AcT) and its overgrowth, the size and the probability of occurrence of hypertension can be estimated (Table 2). Hemodynamic testing is required since the assessment of non-invasive mPAP does not allow for a definite diagnosis $[2,11]$.

\section{Computed tomography and magnetic resonance}

An angio-CT examination is useful in the differential diagnosis, especially in clinical group 4 with $\mathrm{PH}$

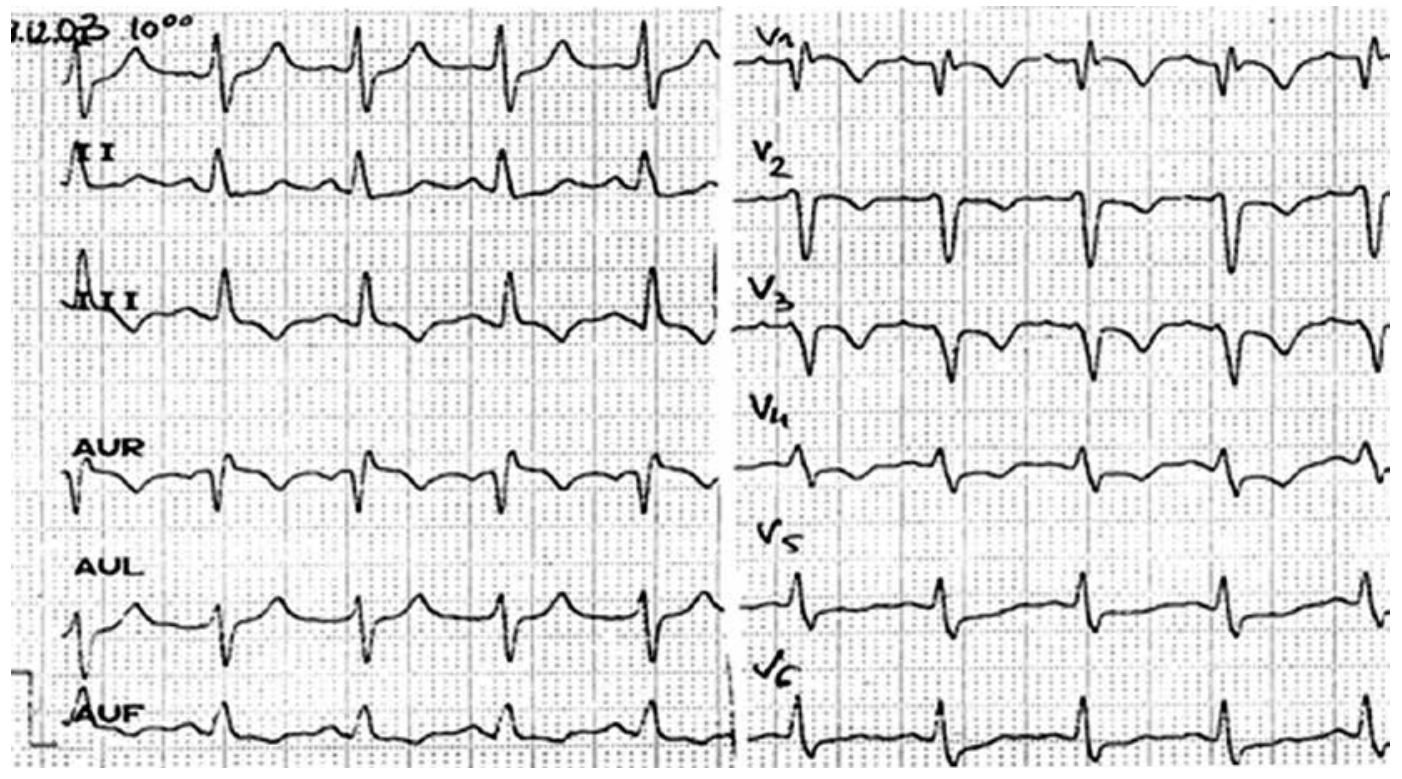

Figure 1. 12-lead ECG. Right axis deviation. Right ventricular hypertrophy and overload 


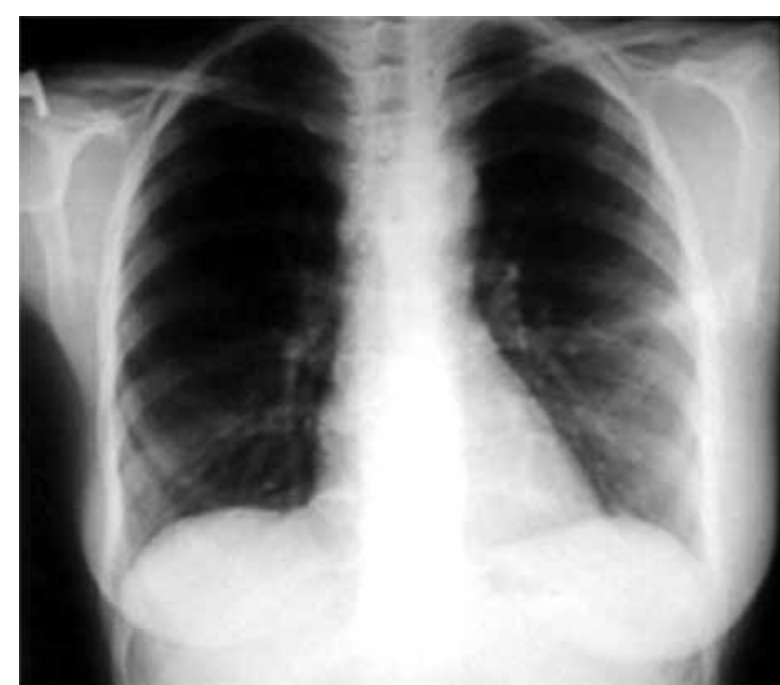

Figure 2. Antero-posterior chest X-ray. Enlarged cardiac waist. Reduced vascular marking in lung peripheral fields

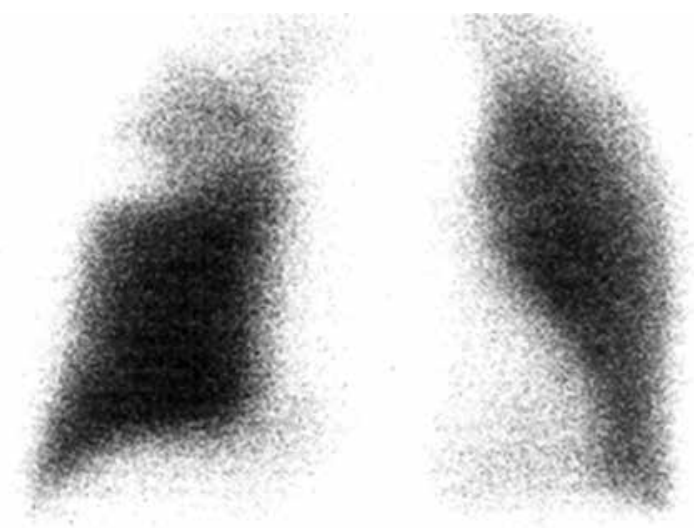

Figure 4. Perfusion scintigraphy. Segmental perfusion defect in chronic thromboembolism

in chronic thromboembolism disease, allowing the identification of organized thrombi in the pulmonary arteries (Figure 3). High-resolution computed tomography (HRCT) allows the precise display of the lung parenchyma. It is especially useful in the differential diagnosis of clinical groups 4,2 , and $1[12,13]$. The magnetic resonance illustration allows the evaluation of the morphology and function of the right ventricle,

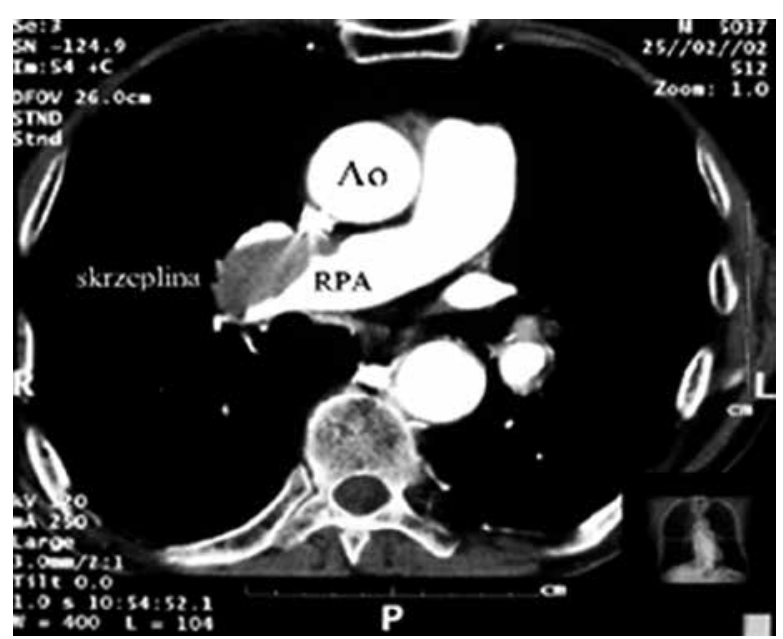

Figure 3. Chest angio-CT. A large thrombus in the right pulmonary artery

together with some of the hemodynamic parameters, which can be used as markers of poor prognosis (reduced stroke volume, increased end-diastolic volume of the right ventricle and reduced left ventricle). This test is especially useful in patients' monitoring and evaluation of the progress of the disease or response to the treatment [14].

\section{Ventilation-perfusion scintigraphy}

Ventilation-perfusion scintigraphy is a screening method in the diagnosis of $\mathrm{PH}$ in patients with chronic thromboembolic disease (clinical group 4) and if within normal limits it excludes this etiology of $\mathrm{PH}$. In the case of disclosure of segmental and larger perfusion defects (Figure 5) it suggests the diagnosis [15]. In $\mathrm{PAH}$ the scintigraphy test is normal or sometimes may disclose subsegmental perfusion defects (Figure 4).

\section{Other additional examinations}

Especially at the beginning of the disease deviations from changes at rest are small or close to normal. Vital capacity of lungs may be reduced. The oxygen partial pressure $\left(\mathrm{pO}_{2}\right)$ at rest is usually normal. The study allows one to assess the degree of obstruction and changes in the lung interstitium in the differential diagnosis of clinical group 3. In all patients basic

Table 2. Probability of a diagnosis of pulmonary hypertension using echocardiography. Based on items [2-4] of the literature

\begin{tabular}{|ll|}
\hline $\begin{array}{l}\text { Probability of PH } \\
\text { presence }\end{array}$ & Echocardiographic parameters \\
Small & - TVIvel $\leq 2.8 \mathrm{~m} / \mathrm{s}(\mathrm{sPAP}<36 \mathrm{~mm} \mathrm{Hg})$ and no other PH symptoms in echocardiography test \\
Medium & - TVIvel $\leq 2.8 \mathrm{~m} / \mathrm{s}(\mathrm{sPAP}<36 \mathrm{~mm} \mathrm{Hg})$ and other $\mathrm{PH}$ symptoms present \\
& in echocardiography test or \\
& - TVIvel $2.9-3.4 \mathrm{~m} / \mathrm{s}(\mathrm{sPAP} 37-50 \mathrm{~mm} \mathrm{Hg})$ independently from other PH symptoms in echo \\
High & - TVIvel $>3.4 \mathrm{~m} / \mathrm{s}(\mathrm{sPAP}>50 \mathrm{mmHg})$ independently from other $\mathrm{PH}$ symptoms in echo \\
\hline
\end{tabular}


examinations must be completed. These examinations include biochemistry, thyroid hormone levels, hematology, antinuclear antibodies, serological tests for HIV, and abdominal ultrasound to rule out liver cirrhosis and portal hypertension [16-18].

\section{Right heart catheterization}

Based on clinical data, echocardiographic data and additional tests, right heart catheterization can be indicated [2]. This study is a key component of the diagnostic algorithm and the gold standard in the diagnostic process. This study assesses: pulmonary artery pressure (systolic, diastolic, mean), pulmonary capillary wedge pressure (PWP), right atrial pressure (RAP), cardiac output (CO), pulmonary vascular resistance (PVR) and systemic vascular resistance in the systemic circulation, the blood pressure and degree of saturation of arterial and mixed blood.

Right heart catheterization is always performed together with the pulmonary vascular reactivity test (usually with the use of nitric oxide, less commonly with epoprostenol or adenosine), because only in patients with a positive result of this test is it advisable to use high doses of calcium channel blockers, which results in an extension of survival time. The criterion of a positive test result is to reduce the reactivity of the absolute value of mPAP below $40 \mathrm{~mm} \mathrm{Hg}$ and by more than $10 \mathrm{~mm} \mathrm{Hg}$ at baseline or at unchanged cardiac output [2].

\section{Diagnostic algorithm of pulmonary hypertension and pulmonary arterial hypertension}

Figure 5 shows an algorithm for diagnosis of pulmonary hypertension. If the clinical and echocardiographic results do not suggest $\mathrm{PH}$, other causes should be looked for or the test should be repeated in a few months. If suggestions are confirmed, common causes

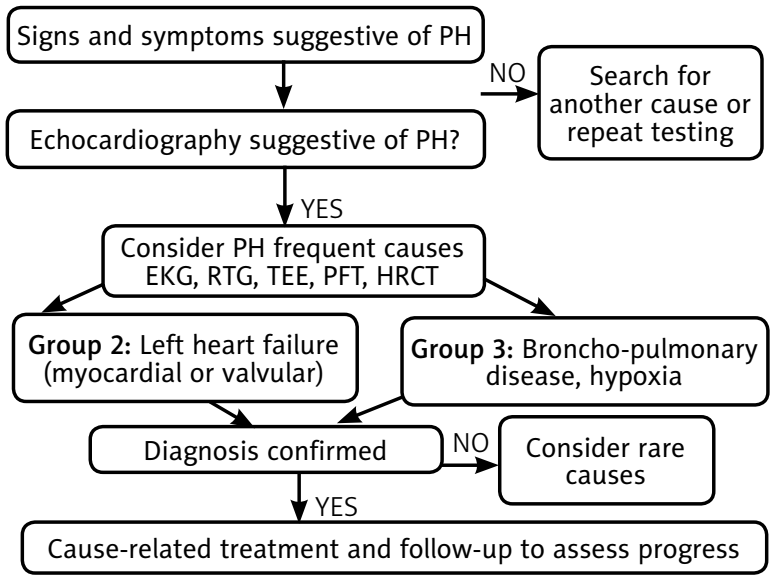

Figure 5. Diagnostic algorithm for pulmonary hypertension. Based on ref. [2-4] of $\mathrm{PH}$ have to be considered, i.e. clinical group $2-\mathrm{PH}$ due to left heart dysfunction; or clinical group $3-\mathrm{PH}$ due to lung diseases/bronchitis and hypoxia. If a disease which is a common cause of $\mathrm{PH}$ is confirmed, it has to be treated and the progression of the disease should be periodically evaluated. If the clinical diagnosis of group 2 or 3 is not confirmed, ventilation-perfusion scintigraphy should be performed to confirm or exclude pulmonary hypertension in the course of thromboembolic disease - clinical group 4 (Figure 6). If scintigraphy is within normal limits a series of tests has to be performed to detect rare causes of $\mathrm{PH}$. When positive tests indicate the disease responsible for pulmonary arterial hypertension, we recognize this disease entity which is clinical group 1 and the corresponding subgroup (for example, 1.3, which means a group of drug-induced clinical pulmonary arterial hypertension). However, when negative results of the test are obtained, we recognize idiopathic PAH (IPAH) or clinical group 1.1.

The diagnostic process of PAH requires a lot of research, the identification of clinical $\mathrm{PH}$ groups, the determination of specific etiology within $\mathrm{PAH}$, and the assessment of hemodynamic and functional disorders. The diagnosis of PAH and particularly IPAH is determined by excluding other causes of $\mathrm{PH}$.

\section{Prognosis for pulmonary arterial hypertension}

Depending on the value of mPAP there are three degrees of severity of the disease: mild, when PAP is less than $35 \mathrm{~mm} \mathrm{Hg}$; moderate, when PAP is within the range of $35-55 \mathrm{~mm} \mathrm{Hg}$; and severe, when mPAP is above $55 \mathrm{~mm} \mathrm{Hg}$. The prognosis depends on the rate of rise of equivalent load of RV and associated with it progressive dysfunction of RV. Developed PAH has a progressive nature. One of the most important prognostic indicators is functional class in a four-graded

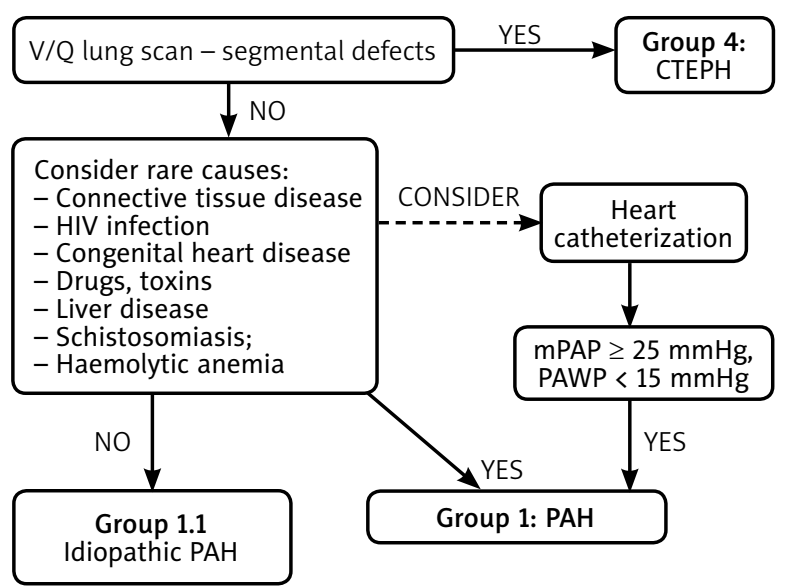

Figure 6. Diagnostic algorithm for pulmonary arterial hypertension. Based on ref. [2-4] 
Table 3. Classification of physical capacity according to WHO

\begin{tabular}{|ll|}
\hline Functional class & Symptom profiles \\
II & No limit on routine physical activity. \\
& Ordinary physical activity does not cause dyspnea or fatigue, chest pain or presyncope \\
Slight limitation of physical activity. & $\begin{array}{l}\text { At rest - without symptoms. Ordinary physical activity causes undue dyspnea or fatigue, } \\
\text { chest pain or presyncope }\end{array}$ \\
& Significant limitation of physical activity. \\
At rest - there is no discomfort. Physical activity at a lower than normal level resulting in \\
excessive shortness of breath or fatigue, chest pain or presyncope \\
IV \\
$\begin{array}{l}\text { Unable to perform any physical activity without accompanying symptoms. } \\
\text { These patients have symptoms of congestive heart failure. } \\
\text { Shortness of breath and/or fatigue may be present even at rest }\end{array}$ \\
\end{tabular}

WHO classification, in which the main criterion is the degree of reduction in exercise capacity (Table 3 ).

In noninvasive studies a bad prognosis is related to patients whose length in the 6-minute walking is less than $380 \mathrm{~m}$ and the concentration of NT-proBNP is more than $1400 \mathrm{pg} / \mathrm{ml}$. In echocardiography examinations the signs of poor prognosis are pericardial effusion, right atrial enlargement evaluated by planimetry, severe deformation of the left ventricle through the interventricular septum and reduced amplitude of tricuspid annular plane systolic excursion (TAPSE) less than $15 \mathrm{~mm}$. In invasive studies indicators of poor prognosis are right atrial pressure above $10-15 \mathrm{~mm} \mathrm{Hg}$, cardiac index reduced below $2.0 \mathrm{l} / \mathrm{min}$ and decreased hemoglobin saturation in mixed venous blood $\left(\mathrm{SvO}_{2}\right)$ less than $65 \%$ [19-25].

\section{Treatment of pulmonary arterial hypertension}

Depending on the functional class, physical activity should be limited, so that maximum exercise does not cause undesirable clinical signs. Staying at high altitude and air travel without the possibility of using oxygen have to be avoided. Patients should limit their consumption of salt. The only possibility of treatment of patients with suspected PAH is sending them to a center involved in the comprehensive diagnosis and treatment of $\mathrm{PAH}$, since early diagnosis and implementation of treatment can delay progress of the disease. In the pharmacological treatment the conventional therapy involves the use of: oral anticoagulants due to the significant involvement of thrombotic processes in the pathogenesis of PAH, oxygen therapy in order to maintain saturation of $>90 \%$, which improves the quality of life, diuretics and cardiac glycoside in advanced right heart failure. The use of digitalis should be applied cautiously in advanced hypoxemia due to the risk of serious ventricular arrhythmias [2-4].
In patients with a positive reactivity test of pulmonary arteries (10\% of patients with $\mathrm{PAH})$, calcium channel blockers (nifedipine, diltiazem, amlodipine) have to be used and in the case of a positive effect treatment should be continued [26, 27].

In the remaining patients with a negative test of reactivity of pulmonary arteries, monotherapy or sequential therapy has to be used. These therapies consist of the following classes of drugs [2-4, 6, 28-31]:

1 . Endothelin receptor antagonists (bosentan, ambrisentan).

2. Prostanoids (epoprostenol [synthetic prostacyclin] and its analogs iloprost and treprostinil). They are given by intravenous or subcutaneous infusion, continuous or intermittently using a nebulizer.

3. Phosphodiesterase inhibitors type 5 (sildenafil and tadalafil administered orally exert antiproliferative effects on diastolic blood pressure and smooth muscle cells of blood vessels).

In severe cases surgery may be considered - heart and lung transplantation [32].

\section{Summary}

Pulmonary hypertension is common in diseases of the heart and lungs, whereas pulmonary arterial hypertension is a rare disease with a progressive course, which escalates over time. It is a disease with a very serious prognosis. A diagnosis is difficult and specific. The aim of the diagnostic procedure is to exclude other causes of observed symptoms and other effects of pulmonary hypertension. The diagnosis and the use of specific therapy requires right heart catheterization. The biggest challenge of PAH therapy is to inhibit proliferative changes in the pulmonary arteries, which leads to a progressive increase in pulmonary vascular resistance and symptoms of right heart failure. According to current guidelines it is recommend to use sequential combination therapy based on drugs of the three presented groups, while 
there is no improvement during application of monotherapy.

\section{References}

1. von Romberg E. Über Sklerose der Lungen Arterie. Deutsch Archiv Klin Med 1891; 48: 197-206.

2. Galiè N, Hoeper MM, Humbert M, et al.; ESC Committee for practice Guidelines (CPG). Guidelines for the diagnosis and treatment of pulmonary hypertension: the Task Force for the Diagnosis and Treatment of Pulmonary Hypertension of the European Society of Cardiology (ESC) and the European Respiratory Society (ERS), endorsed by the International Society of Heart and Lung Transplantation (ISHLT). Eur Heart J 2009; 30: 2493-2537.

3. Simonneau G, Robbins I, Beghetti M, et al. Updated clinical classification of pulmonary hypertension. J Am Coll Cardiol 2009; 54: S43-S54.

4. Grupa Robocza Europejskiego Towarzystwa Kardiologicznego do spraw rozpoznawania nadciśnienia płucnego. Wytyczne dotyczące rozpoznawania i leczenia nadciśnienia płucnego. Kardiol Pol 2009; 67: 11 (supl. 7).

5. Thenappan T, Shah SJ, Gomberg-Maitland M, et al. Clinical characteristics of pulmonary hypertension in patients with heart failure and preserved ejection fraction. Circ Heart Failure 2011; 4: 257-265.

6. Gabby E, Yeow W, Playford D. Pulmonary arterial hypertension is an uncommon cause of pulmonary hypertension in an unselected population: the Armadale Echocardiography Study. Am J Respir Crit Care Med 2007; 175 A713.

7. Humbert M, Sitbon O, Chaouat A, et al. Pulmonary arterial hypertension in France: results from a national registry. Am J Respir Crit Care Med 2006; 173: 1023-1030.

8. Gaine SP, Rubin LJ. Primary pulmonary hypertension. Lancet 1998; 352: 719-725.

9. Tongers J, Schwerdtfeger B, Klein G, et al. Incidence and clinical relevance of supraventricular tachyarrhythmias in pulmonary hypertension. Am Heart J 2007; 153: 127-132.

10. Rich S, Dantzker DR, Ayres SM, et al. Primary pulmonary hypertension. A national prospective study. Ann Intern Med 1987; 107: 216-223.

11. McQuillan BM, Picard MH, Leavitt M, et al. Clinical correlates and reference intervals for pulmonary artery systolic pressure among echocardiographically normal subjects. Circulation 2001; 104: 2797-2802.

12. Resten A, Maitre S, Humbert M, Rabiller, et al. Pulmonary hypertension: CT of the chest in pulmonary venoocclusive disease. AJR Am J Roentgenol 2004; 183: 65-70.

13. Reichelt A, Hoeper MM, Galanski M, et al. Chronic thromboembolic pulmonary hypertension: evaluation with 64-detector row CT versus digital substraction angiography. Eur J Radiol 2009; 71: 49-54.

14. Torbicki A. Cardiac magnetic resonance in pulmonary arterial hypertension: a step in the right direction. Eur Heart J 2007; 28: 1187-1189.

15. Tunariu N, Gibbs SJ, Win Z, et al. Ventilation-perfusion scintigraphy is more sensitive than multidetector CTPA in detecting chronic thromboembolic pulmonary disease as a treatable cause of pulmonary hypertension. J Nucl Med 2007; 48: 680-684.

16. Rich $S$, Kieras $K$, Hart $K$, et al. Antinuclear antibodies in primary pulmonary hypertension. J Am Coll Cardiol 1986; 8: 1307-1311
17. Chu JW, Kao PN, Faul JL, et al. High prevalence of autoimmune thyroid disease in pulmonary arterial hypertension. Chest 2002; 122: 1668-1673.

18. Naeije R. Hepatopulmonary syndrome and portopulmonary hypertension. Swiss Med Wkly 2003; 133: 163-169.

19. D'Alonzo GE, Barst RJ, Ayres SM, et al. Survival in patients with primary pulmonary hypertension. Results from a national prospective registry. Ann Intern Med 1991; 115: 343-349.

20. Eysmann SB, Palevsky HI, Reichek N, et al. Two-dimensional and Doppler-echocardiographic and cardiac catheterization correlates of survival in primary pulmonary hypertension. Circulation 1989; 80: 353-360.

21. Raymond RJ, Hinderliter AL, Willis PW, et al. Echocardiographic predictors of adverse outcomes in primary pulmonary hypertension. J Am Coll Cardiol 2002; 39: 1214-1219.

22. Tei C, Dujardin KS, Hodge DO, et al. Doppler echocardiographic index for assessment of global right ventricular function. J Am Soc Echocardiogr 1996; 9: 838-847.

23. Yeo TC, Dujardin KS, Tei C, et al. Value of a Doppler-derived index combining systolic and diastolic time intervals in predicting outcome in primary pulmonary hypertension. Am J Cardiol 1998; 81: 1157-1161.

24. Forfia PR, Fisher MR, Mathai SC, et al. Tricuspid annular displacement predicts survival in pulmonary hypertension. Am J Respir Crit Care Med 2006; 174: 1034-1041.

25. Wensel R, Opitz CF, Anker SD, et al. Assessment of survival in patients with primary pulmonary hypertension: importance of cardiopulmonary exercise testing. Circulation 2002; 106: 319-324.

26. Humbert M, Sitbon O, Simonneau G. Treatment of pulmonary arterial hypertension. N Engl J Med 2004; 351: 1425-1436.

27. Sitbon O, Humbert M, Jaïs X, et al. Long-term response to calcium channel blockers in idiopathic pulmonary arterial hypertension. Circulation 2005; 11: 3105-3111.

28. Humbert M, Sitbon O, Chaouat A, et al. Survival in patients with Idiopathic, familial, and anorexigen-associated pulmonary arterial hypertension in the Modern Management Era. Circulation 2010; 122: 156-163.

29. Channick RN, Simonneau G, Sitbon O, et al. Effects of the dual endothelin-receptor antagonist bosentan in patients with pulmonary hypertension: a randomised placebocontrolled study. Lancet 2001; 358: 1119-1123.

30. Galiè N, Ghofrani HA, Torbicki A, et al. Sildenafil citrate treatment for pulmonary arterial hypertension. N Engl J Med 2005; 353: 2148-2157.

31. Galiè N, Brundage BH, Ghofrani HA, et al. Pulmonary Arterial Hypertension and Response to Tadalafil (PHIRST) Study Group. Tadalafil therapy for pulmonary arterial hypertension. Circulation 2009; 119: 2894-2903.

32. Salzberg SP, Lachat ML, von Harbou K, et al. Normalization of high pulmonary vascular resistance with LVAD support in heart transplantation candidates. Eur J Cardiothorac Surg 2005; 27: 222-225.

\section{Address for correspondence:}

Marcin Sadowski

Świętokrzyskie Centrum Kardiologii WSzZ

ul. Grunwaldzka 45, 25-735 Kielce, Poland

Phone: +48606906454

E-mail: emsad@o2.pl 